\title{
Diagnosis of asthma in children
}

\author{
J Townshend, S Hails, M Mckean
}

Paediatric Respiratory Unit, Royal Victoria Infirmary, Newcastle upon Tyne NE1 4LP

Correspondence to: $\mathrm{M}$ Mckean m.c.mckean@ncl.ac.uk

BMJ 2007;335:198-202 doi:10.1136/bmj.39234.651412.AE

\section{Children presenting with wheeze are likely to have either atopic asthma or episodic viral wheeze; distinguishing between these has important implications for management}

If it's wheeze it must be asthma, and if it's asthma it must mean bronchodilators and inhaled corticosteroids - simple enough. Indeed, as asthma is so common this paradigm might seem to be logical. The large scale international study of asthma and allergy in childhood (ISAAC) found that the United Kingdom, Australia, and New Zealand had among the highest prevalences, with $15 \%$ of children affected. ${ }^{1}$ Asthma is more complicated, however, especially in children. We are often uncertain whether children who wheeze do have asthma, and some people say that diagnosing asthma in very young children is not possible. An increasing body of evidence suggests that asthma is a complex disorder and that different patterns of illness have different underlying pathogenesis.

Many studies have investigated various treatments in older children with classic allergic asthma, yet relatively few have considered the many young children who have recurrent wheeze. Many common treatments now have a good evidence base, but gaps still exist, such as treatments for the most difficult and severe childhood asthma. Therapeutic advances include both new drugs and new licences for older drugs. For example, the new drug omalizumab and montelukast are now licensed down to 6 months of age. Yet despite an increasing number of therapeutic options, children still die from asthma (23 recorded deaths in $2002^{2}$ ). With this in mind, this first of two articles will review the features of the two most common patterns of childhood wheezing illnesses: atopic asthma and episodic viral wheeze. The second review will focus on management.

\section{How do patients present?}

If one feature consistently points to a diagnosis of asthma, it is wheeze. Wheeze is the end result of narrowing of small airways due to processes that include oedema of the airway wall, contraction of smooth muscle, and mucus plugging. A study of parents of wheezing children found that some thought that wheeze was a sound such as whistling, squeaking, or gasping, whereas others defined it as a different rate, style, or timbre of breathing, and some thought it was the same as coughing. ${ }^{3}$ This is an important reminder that reported wheeze might not be wheezing after all. Associated with asthmatic wheeze is the observation of variable or reversible airways obstruction. ${ }^{4}$ Over the 1980s, however, with an increased recognition of allergy, "asthma" became synonymous with "atopic asthma." For many people, asthma became wheeze plus allergy plus bronchial hyper-responsiveness. ${ }^{5}$ However, this approach failed to recognise those young children and indeed older children and adults who wheeze only with colds, ${ }^{67}$ strongly suggesting more than one phenotype of wheezing illnesses.

\section{Atopic asthma}

The most widely recognised phenotype of wheeze is atopic asthma. This commonly presents as the school aged child who complains of episodic wheeze, cough, and shortness of breath, often with identifiable triggers and other signs of atopy, such as eczema and hay fever. Atopic asthma is more common than non-atopic childhood asthma; as many as $85 \%$ of school aged children with asthma are atopic. ${ }^{8}$ This type of asthma is classically associated with eosinophils and mast cells. Many studies have identified these cells in bronchial tissues and secretions of people with asthma. Increased numbers of eosinophils are known to be associated with increased symptoms of asthma, and using eosinophils as a guide to adjusting corticosteroid treatment has been shown to be an effective strategy for treating asthma in adults. ${ }^{9}$

One area of diagnostic difficulty in childhood asthma is chronic cough. Cough is a common complaint in childhood; up to $10 \%$ of preschool and early school aged children have chronic cough without wheeze at some time. ${ }^{10}$ Although childhood asthma may present with cough, most children who cough without wheeze

\section{SEARCHES AND SELECTION CRITERIA}

This review draws on the chapter on asthma and other wheezing disorders in children in Clinical Evidence, search date October 2006. We searched Medline in January 2007 with the terms asthma, viral induced wheeze, childhood, prevalence, symptoms, diagnosis, management, corticosteroids, and adrenal suppression. We also used the British Thoracic Society/ Scottish Intercollegiate Guidelines Network guideline on the management of asthma 
do not have asthma (box 1). Isolated chronic cough is a poor marker of asthma and, without other typical features of asthma, should always raise the strong possibility of an alternative cause. ${ }^{9}$ However, cough predominant or cough variant asthma undoubtedly exists, possibly because sometimes wheeze is not easily identified. It is associated with bronchial hyper-responsiveness or reversible airways obstruction, both key features of asthma. ${ }^{11}$ Demonstrating these features can help to identify children with cough predominant asthma. In the absence of these features, a short trial of asthma treatment may aid the diagnosis of asthma. ${ }^{12}$ Establishing that improvement in cough is due to treatment rather than coincidence is, however, important, as postviral cough will spontaneously improve. A return of symptoms on discontinuing treatment supports asthma as the diagnosis.

\section{Episodic viral wheezing}

Before the 1980s, wheezy and "chesty" young children were commonly referred to as "wheezy bronchitics."13

\section{Box 1 Causes of chronic cough in childhood}

\section{Chronic suppurative lung disease}

\section{- Cystic fibrosis}

- Immune deficiencies

- Primary ciliary dyskinesia

- Recurrent pulmonary aspiration

- Retained inhaled foreign body

- Chronic bronchitis

- Congenital causes (such as Mounier-Kuhn syndrome) and other less common causes Environmental pulmonary toxic agents

- Exposure to tobacco smoke

- Other environmental pollutants (such as biomass combustion particles)

\section{Airways lesion}

- Compression-for example, lymph nodes, vascular ring

- Malacia, often with an airway infection

Upper airway disease

- Adenotonsillar hypertrophy

- Rhinosinusitis

Oesophageal/swallowing problems

- Aspiration

- Neuromuscular disease

- Tracheo-oesophageal fistula

Interstitial lung disease

- Autoimmune disorders

- Cytotoxic drugs/irradiation

Others

- Protracted bronchitis

- Recurrent viral bronchitis

- Acute respiratory infections and postinfections, pertussis-like illness (parapertussis, adenovirus, mycoplasma, and Chlamydia)

- Increased cough receptor sensitivity

- Functional respiratory disorder (habitual cough or "vocal tic")

- Asthma/asthma-like conditions

- Non-asthmatic eosinophilic bronchitis and allergy

- Side effects of drugs

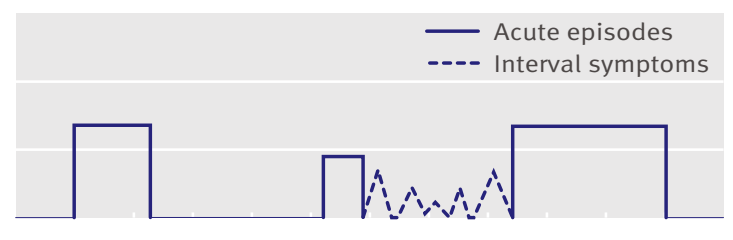

Time

Fig 1 | Timeline of wheeze-a useful tool in the clinic

This describes an illness triggered by the common cold and leading to mucous hypersecretion, inflammation, and bronchoconstriction. Wheezy, rattling children are a common phenotype that we recognise as different from children with atopic asthma: so called "episodic viral wheezers." These children are not considered truly asthmatic and are not included in most studies of the epidemiology of asthma. However, their acute episodes are similar to those of older children labelled as having asthma. Episodic viral wheeze is common; $30-50 \%$ of preschool children have at least one episode. Some young children with atopic asthma start with a pattern of episodic viral wheeze before more persistent features surface, but most of those with pure episodic viral wheeze tend to outgrow their symptoms as they get older. Emerging data on pathophysiology support this as a distinct phenotype. One reason why these children wheeze with viruses is likely to be that they are born with smaller airway dimensions than those who do not wheeze. ${ }^{8}$ In one study, bronchoalveolar lavages were taken from asymptomatic preschool children with atopic asthma, those with episodic viral wheeze, and healthy controls having routine surgery. ${ }^{14}$ Those with atopic asthma had increased numbers of eosinophils and mast cells compared with episodic viral wheezers, who were similar to controls. An experimental viral infection of adults with episodic viral wheeze showed a predominantly neutrophilic inflammatory response without any evidence of eosinophilia. ${ }^{15}$ This pattern of neutrophil activation has also been shown in children with episodic viral wheeze. ${ }^{16}$ The link between inflammation and wheeze, however, is likely to be complex; evidence from the same group indicates that eosinophils may play a role in episodic viral wheeze independent of atopy. ${ }^{17}$

Much remains to be understood about the interaction between viruses and wheezing episodes. Viruses are the major trigger for acute asthma attacks in children and adults. We know that respiratory syncytial virus infection is associated with recurrent wheezing for several months and occasionally years after bronchiolitis. Emerging evidence indicates that subtle differences in the responses of the innate and adaptive immune systems might be responsible for the development of virus associated wheeze. ${ }^{18}$ For example, some people with asthma have a reduced interferon $\gamma$ response to rhinovirus, suggesting a predisposition to viral infection, whereas others have a heightened response with reduced symptoms during colds. A better understanding of why some children wheeze only 
with viruses and others wheeze with many triggers may one day allow us to target treatments more effectively.

\section{Other causes of wheeze}

Other conditions can sometimes cause a wheezy chest (table). These should be considered in children who do not display key features of asthma, have additional clinical features (table), or do not respond to conventional asthma treatment.

\section{What are the key features in the history and examination?}

As with most initial assessments, diagnosis and management are informed by identifying recognised patterns in the history and assessing the severity with additional information gained from the physical examination. Mapping the pattern over time (fig 1) is useful not only in making a diagnosis but also in assessing severity and guiding treatment. Box 2 provides a guide to history taking and examination.

\section{What investigations might help?}

If the child does not respond to initial treatment or needs high doses, some specific tests may help to secure the diagnosis and assess severity more objectively.

Peak expiratory flow monitoring-Usually used in children over 5 years, peak expiratory flow monitoring is useful to establish diurnal variation and the severity of obstruction. Routine measurement is likely to be of

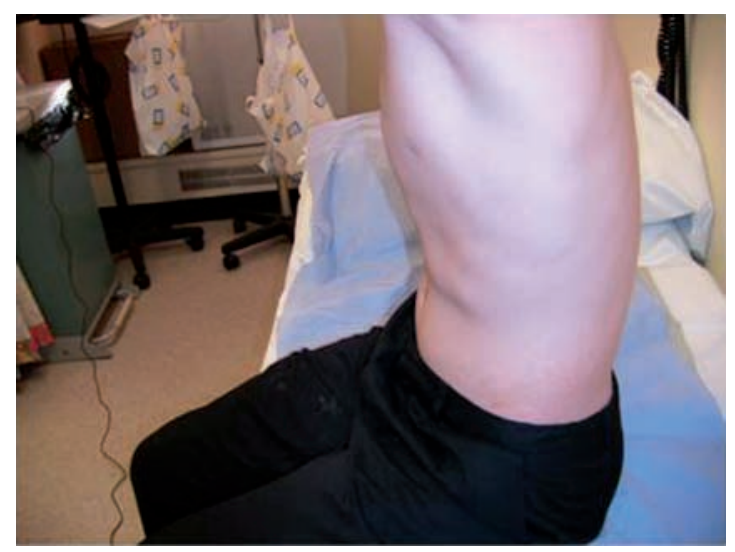

Fig 2 | Hyperinflation and a Harrison's sulcus. Note the slight increase in anterior-posterior diameter resulting from mild bowing of the sternum. Also note the indenting just above the costal margin (Harrison's sulcus). These are often subtle signs that are easily overlooked except in the most severe cases, but they do support recurrent and chronic increased effort of breathing

limited value, with a significant drop-off in reliability of recordings made over long periods of time..$^{19}$ Normal peak expiratory flow values vary widely, so each child should use his or her "personal best" as a guide to how obstructed they are. Consider using peak expiratory flow monitoring in short bursts, especially when treatment is being changed.

Allergy testing - This is not necessary in routine practice. However, where features are atypical or simple

\begin{tabular}{|c|c|}
\hline \multicolumn{2}{|l|}{ Alternative diagnoses in wheezing children } \\
\hline Alerting symptom or sign and possible diagnoses & Clinical clues \\
\hline \multicolumn{2}{|l|}{ Wheeze present from birth } \\
\hline \multicolumn{2}{|l|}{ Structural abnormality: } \\
\hline \multicolumn{2}{|l|}{ Bronchogenic cyst } \\
\hline Vascular ring & Present immediately at birth. Constant wheeze with no variation \\
\hline \multicolumn{2}{|l|}{ Intrabronchial narrowing } \\
\hline Laryngeal problem & Weak cry, stridor \\
\hline Congestive cardiac failure & Signs of heart failure \\
\hline GORD \pm aspiration & History of GORD \\
\hline \multicolumn{2}{|l|}{ Wheeze present shortly after birth } \\
\hline Bronchopulmonary dysplasia & History of prematurity or ventilation \\
\hline \multicolumn{2}{|l|}{ Compromised host defence: } \\
\hline Immunodeficiency & Recurrent bacterial infections and failure to thrive \\
\hline Cystic fibrosis & Persistent cough and poor nutrition \\
\hline Primary ciliary dyskinesia & Persistent nasal discharge and otitis media \\
\hline \multicolumn{2}{|l|}{ Sudden onset in previously well child } \\
\hline Aspiration of foreign body & History of aspiration in most. Unilateral reduced breath sounds \\
\hline \multicolumn{2}{|l|}{ Persistent wet cough } \\
\hline \multicolumn{2}{|l|}{ Compromised host defence: } \\
\hline Cystic fibrosis & Poor growth, clubbing, abnormal chest shape, nasal polyps \\
\hline Immunodeficiency & Recurrent bacterial infections and failure to thrive \\
\hline Bronchiectasis & Purulent sputum \\
\hline \multicolumn{2}{|l|}{ Postviral wheeze } \\
\hline Postbronchiolitic wheeze & Can persist for several months. Diagnosed in absence of other alerting signs \\
\hline Obliterative bronchiolitis & Hyperinflation and fine crepitations. Disabling respiratory symptoms \\
\hline
\end{tabular}


treatments are not working, it may help to establish the presence of atopy and identify specific aeroallergens. Measuring total serum IgE can help to establish atopy as part of the phenotype and, for the most severely affected patients, identify those who might respond to the monoclonal anti-IgE antibody, omalizumab. Skin prick testing with house dust mites, grass pollens, and cat dander will identify atopy in the vast majority of children with asthma. Much evidence exists to link exposure to allergens with symptoms of asthma, but avoidance as a therapeutic option remains controversial. Two Cochrane reviews of avoidance found no evidence of benefit; one was a review of house dust mites (49 trials with 2733 patients), ${ }^{20}$ and the other was a review of air filtration against cat allergen (two trials with 57 patients). ${ }^{21}$ Despite this, many experts in the field as well as the British Thoracic Society/Scottish Intercollegiate Guidelines Network guideline recommend avoidance. For committed families with evidence of house dust mite allergy, avoidance measures such as barrier bed covers may be tried, ${ }^{22}$ and the removal of pets from the home may be tried if the asthmatic child is allergic to that pet.

Pulmonary function tests - Forced spirometry (usually in children over 5 years) can assess airways obstruction (reduced forced expiratory volume in one second and

\section{Box $2 \mid$ A guide to history taking and examination}

\section{Pattern of illness}

- Ask about wheeze, cough, and breathlessness (especially on exercise)

- Clarify parents' understanding of wheeze

- Identify triggers (such as "colds," cold air, dust, pets, and pollens)

- Identify interval (between episodes) symptoms

- Map the pattern over time (fig 1)

- Identify presence of hay fever and eczema

- Ask parents if they have atopic illnesses

- Inquire into features that may suggest an alternative diagnosis (table)

Severity of illness

- Degree of breathlessness-ability to play, run, or walk; too breathless to feed or talk

- Use of treatments-number of puffs and frequency of inhaled bronchodilator; frequency of use of oral corticosteroids

- Emergency healthcare access, including level of treatments given

- Frequency of acute episodes*

- Number of days of school missed*

Examination

During episodes

- Look for widespread wheeze

- Look for increased effort of breathing-ability to do activities and to talk, alertness, oxygen saturations

- Assess pulse rate

- Assess peak expiratory flow (in children over 5 years)

- Assess response to bronchodilator and demonstrate reversible airways

\section{Between episodes}

- Look for hyperexpansion and Harrison's sulci (fig 2)

- Look for clues to other diagnoses (table)

*Very frequent episodes indicate that day to day control may not be adequate and identify a very vulnerable group of children

\section{ADDITIONAL EDUCATIONAL RESOURCES}

British Thoracic Society, Scottish Intercollegiate Guidelines Network. British guideline on the management of asthma: a national clinical guideline. Revised edition November 2005 (www.brit-thoracic. org.uk/Guidelinessince\%201997_asthma_html)

Lung and Asthma Information Agency (www.laia.ac.uk/) -Provides epidemiological data on asthma

Information resources for patients

Asthma UK (www.asthma.org.uk)—Comprehensive information resource on asthma for parents and children, including chat rooms and information on educational holidays

Patient UK. Asthma (www.patient.co.uk/showdoc/ $23068680 /$ )_Provides information on what asthma is and on the different treatment options available

Scottish Intercollegiate Guidelines Network (www.sign. ac.uk/)—Provides a link to the updated guidelines on the management of asthma and the evidence behind the guidelines

British Thoracic Society (www.brit-thoracic.org.uk/)Provides a link to the updated guidelines on the management of asthma and the evidence behind the guidelines

ratio of forced expiratory volume in one second to forced vital capacity; reduced mid-expiratory flows). If obstruction is present, reversibility can be assessed 10 minutes after inhalation of a bronchodilator. If reversibility is absent (that is, less than 15\% change in lung function occurs after use of bronchodilator), specific "challenges," such as exercise and histamine challenges, can be done in a specialist lung function laboratory. These assess bronchial hyper-responsiveness and are believed to have a high negative predictive value for asthma $(86-100 \%)$, but they are less useful as a positive predictive tool (perhaps as low as 55\%), as many children without asthma have bronchial hyperresponsiveness. ${ }^{23}$

Chest radiography-This is rarely helpful in acute asthma, except where air leaks are suspected. It may be useful when a diagnosis other than asthma is suspected.

Other tests - When the diagnosis is in doubt or where severe asthma persists despite common treatments, referral to a specialist clinic is needed. A few patients need specialised lung function tests, bronchoscopy, or computed tomography scanning to rule out other conditions (table).

\section{Conclusion}

Different phenotypes of wheeze are seen in childhood. With the approach set out in this review a child can usually be determined to have atopic asthma, nonatopic asthma, or episodic viral wheeze; with an episodic pattern, persistent features, or both; and with a mild, moderate, or severe pattern. This should help to guide the physician in tailoring treatment to suit the individual child. More detailed guidance on points in the history, examination and investigations that aid 


\section{SUMMARY POINTS}

"Childhood asthma" describes several different clinical phenotypes with different

management strategies

The two most common phenotypes are atopic asthma, more common in school aged children, and episodic viral wheeze, more common in preschool children

Wheeze is a poorly understood symptom, and parents should be asked to clarify what they understand it to be

Wheeze is commonly associated with asthma, but several other conditions can result in recurrent wheezing and should be considered before a diagnosis is made

diagnosis can be found in the British Thoracic Society/ Scottish Intercollegiate Guidelines Network guideline. $^{22}$

Contributors: All authors contributed to the collection of data and to the tex of the paper. MM is the guarantor.

Competing interests: None declared

Provenance and peer review: Commissioned; externally peer reviewed.

1 International Study of Asthma and Allergies in Childhood (ISAAC) Steering Committee. Worldwide variation in prevalence of symptoms of asthma, allergic rhinoconjunctivitis, and atopic eczema: ISSAC. Lancet 1998;351:1225-32.

2 Asthma UK. Where do we stand? Asthma in the UK today. London: Asthma UK, 2004 (available at www.asthma.org.uk).

3 Cane RS, Ranganathan SC, McKenzie SA. What do parents of wheezy children understand by "wheeze"? Arch Dis Child 2000;82:327-32.

4 Silverman M. Childhood asthma and other wheezing disorders. 2nd ed. London: Hodder Arnold, 2002:1-8.

5 Peat JK, Toelle BG, Marks GB, Mellis CM. Continuing the debate about measuring asthma in population studies. Thorax 2001;56:406-11.

6 Martinez FD, Wright AL, Taussig LM, Holberg CJ, Halonen M,

Morgan WJ, et al. Asthma and wheezing in the first six years of life. $N$ Engl J Med 1995;332:133-8.

7 Mckean MC, Leech M, Lambert PC, Hewitt C, Myint S, Silverman M. An adult model of viral wheeze: symptoms and physiology. Thorax 2001;56(suppl III):81-2.

8 Silverman M, ed. Childhood asthma and other wheezing disorders. 2nd ed. London: Hodder Arnold, 2002.
9 Green RH, Brightling CE, McKenna S, Hargadon B, Parker D, Bradding P, et al. Asthma exacerbations and sputum eosinophil counts: a randomised controlled trial. Lancet 2002;360:1715-21.

10 Faniran AO, Peat JK, Woolcock AJ. Measuring persistent cough in children in epidemiological studies: development of a questionnaire and assessment of prevalence in two countries. Chest 1999;115:434-9.

11 Mochizuki H, Arakawa H, Tokuyama K, Morikawa A. Bronchial sensitivity and bronchial reactivity in children with cough variant asthma. Chest 2005;128:2427-34.

12 Bush A. Paediatric problems of cough. Pulm Pharmacol Ther 2002;15:309-15.

13 Chang AB, Glomb WB. Guidelines for evaluating chronic cough in pediatrics: ACCP evidence-based clinical practice guidelines. Chest 2006;129(1 suppl):260-83S.

14 Stevenson EC, Turner G, Heaney LG, Schock BC, Taylor R, Gallagher T, et al. Bronchoalveolar lavage findings suggest two different forms of childhood asthma. Clin Exp Allergy 1997;27:1027-35.

15 Mckean MC, Hewitt C, Lambert PC, Myint S, Silverman M. An adult model of exclusive viral wheeze: inflammation in the upper and lower respiratory tracts. Clin Exp Allergy 2003;33:912-20.

16 Oommen A, Patel R, Browning M, Grigg J. Systemic neutrophil activation in acute preschool viral wheeze. Arch Dis Child 2003;88:529-31.

17 Oommen A, McNally T, Grigg J. Eosinophil activation and preschool viral wheeze. Thorax 2003;58:876-9.

18 Haymann PW, Platts-Mills TA, Johnston SL. Role of viral infections, atopy and antiviral immunity in the etiology of wheezing exacerbations among children and young adults. Pediatr Infect Dis 2005;24(11 suppl):S217-22.

19 Wensley DC, Silverman M. The quality of home spirometry in school children with asthma. Thorax 2001;56:183-5.

20 Gøtzsche PC, Johansen HK, Schmidt LM, Burr LM. House dust mite control measures for asthma. Cochrane Database Syst Rev 2004;(4): CD001187.

21 Kilburn S, Lasserson TJ, McKean M. Pet allergen control measures for allergic asthma in children and adults. Cochrane Database Syst Rev 2001;(1):CD002989.

22 British Thoracic Society, Scottish Intercollegiate Guidelines Network. British guideline on the management of asthma: a national clinical guideline. Revised edition November 2005 (www.brit-thoracic.org. uk/Guidelinessince\%201997_asthma_html).

23 Silverman M, ed. Childhood asthma and other wheezing disorders. 2nd ed. London: Hodder Arnold, 2002:144-72.

Accepted: 29 May 2007

\section{Can I help you?}

So, you want to work for a few weeks, maybe as an "expert," in a developing country? Fine. Drawing on our experiences of both giving and receiving such help in several sub-Saharan countries, we can give some tips on making your trip a success.

Get real-Don't expect to make a big difference. You won't. If you're lucky, you might make a tiny one.

Be self sufficient-Don't expect to be looked after Attending to the needs of visitors can be exhausting and not worth the effort. Arrange your own travel and accommodation via the internet. There will be taxis at the airport: take one.

Forget funding-NGOs will not employ strangers for a few weeks. They can be surprisingly bureaucratic and will demand reports. Pay your own way. You can go anywhere for less than $\$ 1000$ ( $£ 500)$ and then live well on $\$ 50$ a day.

Forget litigation-Your defence society may look sympathetically on voluntary work. If not, don't worry. You will not be sued.

Forget snakes, just get the jabs and take the tablets - The biggest risks are malaria, alcohol, and road accidents. Get off the minibus if the driver is intoxicated.

Take your mobile phone-You are visiting a different continent, not a different planet.

Stay celibate-Take post-exposure prophylaxis if you will be risking HIV infection at work.
Learn the lingo-Trying to greet patients in their language will raise a laugh and be appreciated.

Stay cool-When thwarted by the lack of drugs or baffled by Byzantine care systems, do not vent your frustrations on the staff. They may share your feelings. Remember life went on there before you arrived and will do so again after you leave.

Take a torch-In towns do not go out after dark: you may escape being mugged, but falling into a pothole is quite likely. Arrange personal medical insurance.

Be honest-Do not promise further help unless you know you will deliver.

Be polite-Ask permission before taking photographs of patients.

Provide feedback-Once you're back home, email comments, photographs, and thanks to your hosts. Copy any reports or articles on the trip to them.

Compromise-Keep asking how you can help. Do not do only what you want to. Try to do what those who work there want.

Have fun-Keep your sense of humour. If you don't have one, don't go.

Robert Todd Scott retired GP, Glasgow kayandbob.scott@dsl.pipex.com Jane Bates manager, Tiyanjane Clinic

Jessica Mack programme manager, palliative care Queen Elizabeth Central Hospital, Malawi 